\title{
A PESQUISA HISTÓRICA E A HISTÓRIA DA EDUCAÇÃO
}

\author{
Lucia Mara de Lima Padilha ${ }^{1}$ \\ Maria Isabel Moura Nascimento ${ }^{2}$ \\ Universidade Estadual de Ponta Grossa - UEPG
}

\section{RESUMO}

O presente artigo aborda questões referentes ao papel do pesquisador em historia e historia da educação, perante a escolha do recorte histórico, do fato histórico, das fontes históricas e do referencial teórico a ser utilizado para a análise do objeto pesquisado. Discorre brevemente sobre as concepções sobre a história e a importância da escolha da concepção teórica a ser utilizada na pesquisa, pois, independente do método o importante é a clareza do que se quer evidenciar na análise histórica de um objeto de estudo. Destaca que para a pesquisa em história da educação faz-se necessário ter o entendimento sobre os fins da educação presentes em cada período histórico da humanidade, pois, desta forma o pesquisador poderá contribuir para com a elaboração de um conhecimento científico que não privilegie apenas as classes dominantes, mas também, os excluídos historicamente.

Palavras-chave: História; História da Educação; Pesquisa.

\section{HISTORICAL RESEARCH AND HISTORY OF EDUCATION}

\section{ABSTRACT}

This article addresses issues relating to the role of the researcher in history and history of education, because he is the one who chooses the historical period, the historical fact, the historical sources and the theoretical framework to analyze the researched object. It talks briefly about history conceptions and the importance of choosing the theoretical concept to be used in research, because regardless the method, it is more important to clearly comprehend what do you intent to evidence through the historical analysis of the object. It highlights that for research in history of education it is necessary to understand of the purposes of education in each historical period of humanity, because this way the researcher will be able to contribute in developing a scientific knowledge that not only favors upper ruling classes, but also the historically excluded ones.

Keywords: History; History of Education; Research.

\section{Introdução}

Escrever sobre a história ${ }^{3}$ de uma sociedade depende da escolha do historiador, é ele quem irá definir qual o fato histórico que deseja pesquisar, o recorte histórico, e, principalmente qual será o referencial teórico a ser utilizado na análise dos fatos a serem evidenciados. O fato histórico é, portanto, o ponto de partida da análise e interpretação do historiador sobre a "verdade histórica" ${ }^{4}$ de um determinado período da história da humanidade. 
Ao escolher o fato histórico a ser pesquisado o historiador delimita um acontecimento da vida social, sempre baseado numa teoria de referência que determina a seleção dos fatos e das fontes ${ }^{5}$ históricas a serem utilizadas na pesquisa. $\mathrm{O}$ recorte histórico dependerá da intenção do historiador, trata-se de um acontecimento "[...] particularmente qualificado na medida em que por causa da incidência sobre outros acontecimentos, e, portanto sobre o curso da história, que o qualifica como fato histórico, ou seja, como fato do qual se ocupa a ciência da história" (SCHAFF, 1995, p.233). Deste modo, o fato histórico e o historiador possuem uma relação contínua, sendo a história uma interação entre o historiador e o fato histórico num processo dialógico infinito entre o passado e o presente.

Ao delimitar o fato histórico o historiador tem em suas mãos o poder de decidir se apresentará esses fatos como uma simples descrição, ou analisará e explicará a luz de um referencial teórico, as relações que esse fato tem com a totalidade complexa de uma sociedade.

[...] O historiador não pode escapar ao papel ativo que lhe pertence, como sujeito que conhece, na relação cognitiva que é o conhecimento histórico; e porque não pode evitar a introdução do fator subjetivo no conhecimento que é sempre - de certo por definição- "parcial", "partidário", na medida em que as perspectivas cognitivas do historiador são condicionadas pelas relações e interesses sociais próprios de sua época e do seu meio (SCHAFF, 1995, p.240).

Deste modo, os fatos históricos são explicados de diferentes formas, e por muitas vezes contraditórias, pois, o modo de compreender a relação entre esses fatos difere de historiador para historiador, o posicionamento teórico de cada um dependerá do modo como ele compreende, avalia e explica a história, ou seja, os resultados do trabalho do historiador dependem de sua personalidade, da sua formação teórica que dará embasamento para as suas análises, bem como, das convicções pessoais que são determinadas pelo contexto social e econômico no qual ele vive.

Alguns historiadores preferem a explicação dos fatos de maneira genérica se preocupando em explicar os fenômenos pela sua história como uma sucessão de acontecimentos; outros historiadores preferem a explicação causal e se propõem a explicar as causas que produziram ou contribuíram para que um determinado acontecimento ocorresse de acordo com uma determinada lei, indicando o fim e os meios que os homens se propunham a atingir por meio dessas ações (SCHAFF, 1995).

Um recurso utilizado para a compreensão de um fato histórico é o estudo das fontes históricas, que consiste no levantamento de discursos políticos, de documentos oficiais, das memórias iconográficas, bibliografia, entre outras, existente sobre um determinado período histórico. No entanto, ao utilizar essa metodologia, o pesquisador deverá escolher entre duas possibilidades: descrever de maneira simples e integral o conteúdo contido nessas fontes; ou procurar refletir historicamente a fim de compreender e tentar reconstruir as intenções contidas nessas fontes, ou seja, o que as pessoas que as criaram queriam que os outros compreendessem e pensassem daqueles acontecimentos.

A primeira possibilidade, ao se utilizar essa metodologia, seria a de se limitar a observar a fonte como objeto de estudo a partir de sua forma imediata, ou seja, “[...] reduzir o complexo ao simples; é passar do particular ao geral; é chegar a conceitos gerais, por isso mesmo, simples e abstratos, dotados exatamente por causa do seu caráter abstrato, de validade universal" (SAVIANI, 2012, p. 62). Ou seja, reconhecer que só é valido ao conhecimento o que é dado empiricamente a partir da observação imediata. 
A outra forma de se utilizar as fontes como objeto de pesquisa para se compreender um fato histórico, diz respeito ao processo de compreensão da essência dos fenômenos e não apenas a aparência que é dada imediatamente, pois, as fontes históricas não falam por si só, e sim a partir da análise do historiador.

Com efeito, não se trata de considerar as fontes como origem do fenômeno histórico considerado. As fontes estão na origem, constituem o ponto de partida, a base, o ponto de apoio da construção historiográfica que é a construção, no plano do conhecimento, do objeto histórico estudado. Assim, as fontes históricas não são a fonte da história, ou seja, não é delas que brota e flui a história. Elas enquanto registro, enquanto testemunhos dos atos históricos são a fonte do nosso conhecimento histórico, isto é, é delas que brota, é nelas que se apoia o conhecimento que produzimos a respeito da história (SAVIANI, 2004, p.6).

Parte-se do empírico, ou seja, das fontes que representam o objeto concreto sem clareza, para uma análise dos conceitos e determinações mais simples, posteriormente, quando atingido esse ponto "[...] faz-se necessário percorrer o caminho inverso chegando pela via da síntese, de novo ao objeto, agora não mais entendido como "a representação caótica de um todo", mas como "uma rica totalidade de determinações e de relações numerosas" (MARX, 2003, p.229 contribuição para crítica). Ou seja, parte-se da sincrese até a síntese como resultado de toda uma análise sobre o objeto pesquisado.

\section{As diversas concepções de história}

O referencial teórico a ser utilizado pelo pesquisador será de suma importância no processo de escolha da metodologia, das fontes de pesquisa, do recorte histórico e da análise dos dados coletados. Será a partir da escolha da concepção teórica a se utilizada que o pesquisador em história irá refletir sobre seu objeto de estudo. Dentre as concepções teóricas podem-se citar três, as quais serão brevemente discorridas a seguir.

$\mathrm{Na}$ Concepçãa Positivista ${ }^{6}$ da história existe a neutralidade de valores na produção do conhecimento histórico. Para o positivismo a sociedade é regida por leis naturais que determinam a vida em sociedade, independente da vontade e das ações dos homens e ao explicar a sociedade o historiador deve limitar-se a descrever a causa dos fenômenos de forma objetiva e neutra de valores e ideologias, uma teoria "fundada em fatos, sustentada, em última instancia, por observação. Dado factual e observação [...] termos que se remetem: um alude o outro. O que é dado (factual) é [...] o que se pode observar o que se pode ver" (ARANA, 2007, p. 14).

Essa forma de compreender a sociedade leva o positivismo a negar o condicionamento histórico-social do conhecimento. "[...] só analisa os fundamentos sociais do pensamento pré-científico [...] uma análise da relação entre o saber e as classes sociais são contraditórias com o quadro metodológico fundamental do positivismo" (LOWY, 1998, p. 18). Deste modo, a história, do ponto de vista positivista, é escrita como uma sucessão de acontecimentos históricos direcionados para o progresso da humanidade a fim de alcançar o estado positivo.

Para Comte (1978) as ideias conduzem e transformam o mundo e é a evolução da inteligência humana que comanda o desenrolar da história e as ciências e o espirito humano se desenvolve por meio de três fases distintas: a teológica; a metafisica; e a positiva, ou seja, a Lei dos três estados: O primeiro Estado consiste no teológico no qual a explicação dos fatos ocorre por meio das vontades que estão além das vontades dos 
homens, a vontade é sempre do divino e o mundo só é compreendido por meio dos deuses e espíritos, ou seja, a natureza íntima dos seres, as causas primeiras e finais de todos os efeitos; O segundo Estado é o metafísico que substitui os deuses por princípios abstratos atribuídos a natureza, é o estado transitório no qual se faz a passagem do estado teológico para o metafísico; O terceiro é o Estado Positivo no qual o espírito renuncia a procura dos fins últimos e a noção de causa é por ele substituída pela noção de lei, é o estado da razão humana, nele o uso do raciocínio e da observação devem descrever os fatos. A visão positiva dos fatos desconsidera as causas dos fenômenos e torna-se a pesquisa de suas leis, entendidos com relações constantes em fenômenos observáveis (COMTE, 1978).

Para o positivismo o conhecimento científico é a única forma de conhecimento verdadeiro e somente pode-se afirmar que uma teoria é correta se ela foi comprovada através de métodos científicos válidos. "A determinação dos fatos históricos, através da pesquisa erudita em documentos e em fontes primárias em geral, consistiria na principal tarefa da história" (LOPES, 1989, p. 23). A verdadeira filosofia e a verdadeira ciência, diz o positivismo, atêm-se ao dado; positivo diz-se o que é dado, o que efetivamente está ao alcance do homem conhecer; o que, por seu modo de ser dado, por seu modo de presença na relação do conhecimento, não se pode desprezar; o objeto é o que se tem minimamente determinado a seu respeito; Positivo diz-se o dado empírico, tudo que se expõe tudo o que se impõe empiricamente, por meio da experiência visível (ARANA, 2007).

Para o Materialismo Histórico e Dialético ${ }^{7}$ compreender a história da humanidade pressupõe entender que a sociedade está dividida em duas classes antagônicas, e, portanto com interesses diferentes. Para Marx a história é entendida de muitas formas e não segue um curso unilinear e evolutivo.

Os homens fazem sua própria história, mas não a fazem como querem; não a fazem sob circunstâncias de sua escolha e sim sob aquelas com que se defrontam diretamente, ligadas e transmitidas pelo passado. A tradição de todas as gerações mortas oprime como um pesadelo o cérebro dos vivos. E justamente quando parecem empenhados em revolucionar-se a si e às coisas, em criar algo que jamais existiu, precisamente nesses períodos de crise revolucionária, os homens conjuram ansiosamente em seu auxílio os espíritos do passado, tomando-lhes emprestado os nomes, os gritos de guerra, as roupagens, a fim de apresentar a nova cena da história do mundo nesse disfarce tradicional e nessa linguagem emprestada. (MARX; ENGELS, 1979, p 203).

Nas relações sociais exercidas pelos homens cujo fundamento é o trabalho, ocorre a divisão do trabalho, que é sempre determinado pelas relações de produção existentes num período histórico. Essa divisão apresenta vários estágios de desenvolvimento que determinam quais serão as relações entre os homens, no que diz respeito à força de trabalho, os meios de produção e a propriedade privada. Com essa divisão social do trabalho ocorre,

[...] simultaneamente a repartição do trabalho e dos seus produtos, a distribuição desigual tanto em qualidade como em quantidade; dá, portanto, origem à propriedade, que aqui já corresponde, aliás, à definição dos economistas modernos segundo a qual é constituída pela livre disposição da força de trabalho de outrem. De resto, divisão do trabalho e propriedade privada são expressões idênticas - na primeira, enuncia-se relativamente à atividade o que na segunda se enuncia 
relativamente ao produto desta atividade (MARX; ENGELS, 1979, p. 23).

A primeira forma de propriedade corresponde ao período primitivo, no qual o homem vivia em comunidade, assentada sobre a propriedade comum da terra e unida por laços de sangue. "[...] A divisão do trabalho é, então, muito pouco desenvolvida e limita-se a constituir uma extensão da divisão do trabalho natural que existia no âmbito da família" (MARX; ENGELS, 1979, p.9). Com as transformações ocorridas na sociedade primitiva, devido ao emprego de novas formas de trabalho e o uso das terras para a agricultura, aumentou a produção dos bens materiais, e desta forma, começou a exploração do homem pelo homem.

A sociedade, até então homogênea, passa a dividir-se em classes antagônicas, a propriedade, bem comum de todos os membros da tribo, passa a ser privada. Nesta segunda forma de propriedade, a divisão social do trabalho está mais evoluída e os homens exercem coletivamente "[...] o seu poder sobre os escravos que trabalham para eles, o que os liga à forma da propriedade comunitária." (MARX; ENGELS, 1979, p.10).

A terceira forma de propriedade corresponde a feudal, na qual o escravo torna-se servo que produziria os bens para o seu senhor. Nesta estrutura, da mesma forma como ocorria na sociedade baseada na propriedade comunitária, a exploração do homem pelo homem continuou, só que numa nova configuração, agora se explorava o trabalho dos servos e não mais dos escravos. Na sociedade Capitalista a exploração do trabalho se dá nas relações entre a burguesia e o proletário, o trabalho livre e assalariado, subordinado ao capital, faz com que o homem não mais atue sobre a natureza, seu trabalho é realizado de maneira alienada.

Nos primeiros tempos da História, por quase toda parte, encontramos uma disposição complexa da sociedade, em várias classes, uma variada gradação de níveis sociais. Na Roma antiga, temos patrícios, cavaleiros, plebeus, escravos. Na Idade Média, senhores feudais, vassalos, chefes de corporação, assalariados, aprendizes, servos. Em quase todas estas classes, mais uma vez, gradações secundárias. A Sociedade burguesa moderna, que brotou das ruínas da sociedade feudal, não aboliu os antagonismos das classes. Estabeleceu novas classes, novas condições de opressão, novas formas de luta no lugar das antigas. (MARX, 1975, p. 9)

Como um ser histórico, o homem se relaciona socialmente, e, nestas relações sociais produz, por meio do trabalho: os bens materiais; as instituições sociais; e as ideias e concepções humanas. Deste modo o homem, “[...] é uma parte da natureza e ao mesmo tempo ultrapassa a natureza; comporta-se livremente com as próprias criações, procura destacar-se delas, levanta o problema do seu significado e procura descobrir qual o seu próprio lugar no universo" (KOSIK, 2002, p. 127).

Na concepção materialista para se compreender a história parte-se da produção dos bens materiais, a análise da história da sociedade deve se voltar para os modos de produção e as relações de trabalho que serão determinantes para a compreensão das ideias transmitidas, dentre elas a educação. A produção dessas ideias está ligada diretamente com a atividade material e o intercâmbio dos homens, pois não "[...] é a consciência que determina a vida, mas sim a vida que determina a consciência" (MARX; ENGELS, 1979, p. 26).

A produção das ideias está intrinsicamente ligada com as questões ideológicas presentes na sociedade, sendo esta um processo subjetivo consciente, todavia um 
fenômeno objetivo e subjetivo involuntário produzido pelas condições objetivas da existência social dos indivíduos.

[...] Os indivíduos que constituem a classe dominante também têm, entre outras coisas, consciência, e daí que pensem; na medida, portanto, em que dominam como classe e determinam todo o conteúdo de uma época histórica, é evidente que o fazem em toda a sua extensão, e portanto, entre outras coisas, dominam também como pensadores, como produtores de ideias, regulam a produção e a distribuição de ideias do seu tempo; que, portanto, as suas ideias são as ideias dominantes da época. (MARX; ENGELS, 1979, p. 47).

A ideologia é um processo em que as ideias da classe dominante tornam-se preponderantemente ideias de todas as classes sociais. Em cada época as ideias dominantes são as ideias das classes que detêm o poder, o material dominante da sociedade é a classe que é a força material. Quem tem à disposição os meios de produção material obviamente dispõe dos meios de produção espiritual. (MARX; ENGELS, 1979). A classe dominante possui, entre outras coisas, a consciência, sendo assim determina e domina como classe todo o âmbito de uma época histórica.

Além de procurar fixar seu modo de sociabilidade através de instituições
determinadas, os homens produzem ideias ou representações pelas quais
procuram explicar e compreender sua própria vida individual, social, suas
relações com a natureza e com o sobrenatural. Essas ideias ou
representações, no entanto, tenderão a esconder dos homens o modo real
como suas relações sociais foram produzidas e a origem das formas
sociais de exploração econômica e de dominação política (CHAUI, 1980,
p. 8).

Para que isso ocorra é preciso que a classe detentora das condições materiais, além de produzir suas próprias ideias, também a distribuam por meio da educação, da religião, dos costumes e dos meios de comunicação disponíveis. Todavia essas ideias não revelam a realidade real, mas representam a aparência social.

O termo História Nova foi utilizado por Jacques Le Goff, em 1978, como título do livro La Nouvelle Historie. Tem uma tradição própria, a dos fundadores da revista Annales d'histore économique et sociale. Quando Lucien Febvre e Marc Bloch lançaram em Estrasburgo, em 1929, uma revista que retomava, modificado, um velho projeto de Lucien Febvre de uma revista internacional de história econômica que abortara, suas motivações eram de várias ordens (LE GOFF, 1993). Na concepção da História Nova, a história está sob a influência substancial das ciências sociais: sociologia, antropologia, filosofia e nasceu a partir de uma reação ao positivismo e na sua origem,

[...] sabemo-lo, situam-se uma vontade de reação contra a história "positivista", um cuidado de ampliação em todas as direções: o historiador "quer-se e faz-se economista, sociólogo, antropólogo, demógrafo, psicólogo, linguista". Mas, enquanto Henri Berr preocuparase em formular uma doutrina da síntese histórica (era ele filósofo de formação), Lucien Febvre e Marc Bloch pregaram sobretudo mediante o exemplo (GLÉNISSON, 1979, p. 230). 
O movimento da Historia Nova divide-se em três fases distintas: a primeira fase, iniciada em 1920, diz respeito aos embates contra a história tradicional positivista, geração de Annales que lutou contra a história política (história narrativa - acontecimentos fatual) com destaque para a crítica de Lucien Febvre em relação à análise feita de sociedade sob o viés do materialismo histórico e a recusa de uma história simplista. "Recusar a história superficial e simplista que se detém na superfície dos acontecimentos e investe tudo num fator" (LE GOFF, 1993, p. 41); a segunda fase ocorreu em 1946 e centrou-se sobre os conceitos de estrutura e conjuntura com novos métodos e propostas para que ocorresse uma história serial e de longa duração, longa duração das ideias dos sentimentos e das crenças destruindo o anacronismo, ou seja, "a história caminha mais ou menos depressa, porém as forças profundas da história só atuam e se deixam apreender no tempo longo" (LE GOFF, 1993, p. 46); Neste sentido, a história do curto prazo é incapaz de apreender e explicar as permanências e as mudanças. Este é o papel da nova história: fazer com as mudanças sejam melhor apreendidas; a terceira fase, em 1968, caracteriza-se pela fragmentação dos representantes da Historia Nova. Além destas três fases, na atualidade, apresenta-se uma quarta fase, a da Nova História Cultural voltada para a investigação da cultura e suas práticas questionando os métodos e objetivos da história em geral. Os historiadores dessa quarta fase continuam com o ideal dos Annales, ou seja, buscam pela compreensão das leis que regem as práticas coletivas.

Na concepção da Historia Nova a história é global e total, não existe uma historia econômica e social, mas sim uma história pura e simples. A atividade da História Nova reside em colocar em evidencia novos problemas, tendo como fundamentos substituir a historia narrativa descritiva da história tradicional por meio da análise histórica de um problema que contemple o tempo presente; trazer novas contribuições para a história a partir de um diálogo com as ciências sociais e humanas a fim de compreender a totalidade da sociedade; ampliar o campo da história com uma multiplicidade de documentos históricos, documentos escritos, figurados, produtos de escavações arqueológicas, fontes orais, fotografias, filmes, entre outros (LE GOFF, 1993).

Para a História Nova a realidade é social e culturalmente construída, sendo o movimento da história um diálogo com atribuições de valores entre constante entre o passado e o presente e vice e versa. O papel do historiador é o de procurar distinguir as diferentes durações históricas em parceria com a história política, econômica, social e cultural assumindo diversas formas como: a história das concepções globais da sociedade ou história das ideologias; história das estruturas mentais, história das mentalidades, história do imaginário, história do simbólico.

\section{Historia e História da Educação}

A educação está presente em todas as sociedades, de maneira simples e homogênea nas comunidades primitivas; de modo complexo e diversificado, nas sociedades atuais. “[...] Não há prática social na qual estejamos mais duradouramente inseridos que a educação, individual ou coletivamente. Quer em uma ou em outra perspectiva, trata-se de uma prática social histórica" (LOPES, 1986). Por meio da educação as pessoas se comunicam tendo em vista objetivos que não o de educar e, no entanto, educam e se educam (SAVIANI, 1986). Deste modo, a educação é,

[...] um processo social de formação de gerações, subsidiada em fundamentos prático-teóricos de uma dada sociedade, com conteúdos determinados pela produção de suas relações sociais e se expressam num projeto político. Nesse sentido, um projeto de educação para o país pode 
assumir diferentes conteúdos e objetivos em virtude do movimento histórico. (CAVAZOTTI, 2003, p.68).

Nas sociedades primitivas, denominadas tribais, o homem vivia em comunidade, assentada sobre a propriedade comum da terra e unida por " [...] laços de sangue, os seus membros eram indivíduos livres, com direitos iguais. O que era produzido em comum era repartido com todos, e imediatamente consumido" (PONCE, 1963, p.15). A educação acontecia naturalmente, as crianças imitavam e reproduziam os atos realizados pelos adultos em suas atividades rotineiras como a pesca e a caça. Com as transformações estruturais ocorridas neste período histórico a sociedade, até então homogênea, passa a dividir-se em classes antagônicas, a propriedade, bem comum de todos os membros da tribo, passa a ser privada propiciando assim a divisão da humanidade.

Consequentemente à divisão do trabalho, a educação que até então acontecia de forma espontânea passa a ter objetivos definidos, sendo destinada apenas para a classe dominante, pois a mesma não tendo responsabilidades com o trabalho braçal dispunha de tempo livre para realizar as atividades de lazer. "E é aí que se localiza a origem da escola. [...] como se sabe, deriva do grego e significa, etimologicamente, o lugar do ócio" (SAVIANI, 2007, p.9). Essa escola, criada na antiguidade, desempenhou um importante papel na propagação das desigualdades sociais.

Essa desigualdade esteve presente também na educação do período feudal que passa a ser estritamente religiosa sob o poder do cristianismo da Igreja Católica, que se constitui numa espécie de Estado e, "[...] a partir do momento em que as escolas profanas, herdadas da Antigüidade, acabaram de desaparecer, essas escolas religiosas tornam-se o único instrumento através do qual se adquire e transmite a cultura" (MARROU, 1975 p.512). A Igreja procurou desenvolver uma ação educativa sobre a comunidade com o intuito de aumentar "[...] cada vez mais o poder civil, primeiro ligando-se a ele, depois tomando o seu lugar e fazendo o papel de reguladora formativa e administrativa" (CAMBI, 1999, p.126).

Com o surgimento da burguesia, ocorreram mudanças políticas, econômicas e sociais que consequentemente refletiram na educação, as escolas monásticas, localizadas em lugares de difícil acesso, já não atendiam a necessidade da nova classe emergente. A burguesia reclamava por escolas criadas nas cidades, uma vez que o comércio em desenvolvimento exigia um novo tipo de instrução. Surge então a Universidade, cuja fundação "[...] permitiu que a burguesia participasse de muitas vantagens da nobreza e do clero, que até então lhe tinham sido negadas. [...] A conquista de um título universitário elevava o burguês quase ao nível da nobreza" (PONCE, 1963, p. 97).

No entanto, a dualidade da educação continuou com a conquista da burguesia, pois, as massas populares não tiveram acesso à educação, mesmo com a criação das escolas primárias administradas e custeadas pelas cidades, e como "[...] para a igreja e para o senhor feudal a escola nunca significou ilustração popular, também para a burguesia, pelo menos nesse momento histórico, ela não tinha esse sentido" (PONCE, 1963, p.101).

Mesmo com todas as modificações conjunturais, ocorridas durante o processo de desenvolvimento da sociedade primitiva até o surgimento da classe burguesa, a estrutura baseada na diferença das classes não se modifica, e a educação correlata do "[...] processo de surgimento da sociedade de classes que, por sua vez, tem a ver com o processo de aprofundamento da divisão do trabalho" (SAVIANI, 2007, p.9), continua a ser destinada apenas àqueles que detêm o poder econômico nas mãos.

Em uma sociedade dividida em classes antagônicas a educação apresenta fins definidos, a base dessa sociedade, suas ideias, instituições e por vez a educação, são 
reflexos das condições materiais, pois, é a partir dessas condições e do trabalho que os homens constroem, transformam e fazem a história de uma sociedade.

O processo de produção da existência humana é um processo social; ser humano não vive isoladamente, ao contrário, depende de outros para sobreviver. Há interdependência dos seres humanos em todas as formas da atividade humana; quaisquer que sejam suas necessidades - da produção de bens à elaboração de conhecimentos, costumes, valores... -, elas são criadas, atendidas e transformadas a partir da organização e do estabelecimento de relações entre os homens (ANDERY, 2007, p.11).

Nessa sociedade as relações de trabalho, e, por sua vez, a elaboração do conhecimento é desigual. Enquanto a maioria dos homens realiza o trabalho braçal, apenas uma minoria, por meio do trabalho intelectual, produz o conhecimento. Deste modo, as ideias produzidas pelos homens são produtos de suas relações com as atividades concretas, materiais, no processo de existência da humanidade. "A produção de ideias, de representações e da consciência está em primeiro lugar direta e indiretamente ligada à atividade e ao comércio material dos homens, é a linguagem da vida real" (MARX; ENGELS, 1979, p. 25).

A produção dos bens materiais e o desenvolvimento da história dos homens dependem das suas condições materiais, das necessidades que se apresentam durante sua vida e da forma como ele irá satisfazer a mesmas. Em uma sociedade de classes, baseada na propriedade privada, as condições econômicas resultam em conflitos entre as classes, que serão refletidos na produção e na transmissão de ideias.

Tanto o processo de construção de conhecimento cientifico, quanto seu produto, refletem o desenvolvimento e a ruptura ocorridos nos diferentes momentos da historia. Em outras palavras, os antagonismos presentes em cada modo de produção e as transformações de um modo de produção a outro serão transpostos para as ideias cientificas elaboradas pelo homem (ANDERY, 2007, p.13).

A história contada, na maioria da literatura, é a daqueles que venceram em cada período histórico da humanidade, é a história transmitida pela classe dominante de cada época. A educação "[...] possui uma história (que foi ou não escrita). E produz uma história (que poderá ou não ser escrita)." (LOPES, 1986, p.12). Ressaltando que, a história sobre a educação de uma sociedade também é aquela que corresponde aos interesses da classe detentora do poder, que "[...] escreveram a sua própria História e suas próprias práticas educativas, relegando, rejeitando e ocultando todas as outras práticas educativas que se desenvolviam na própria constituição das sociedades" (LOPES, 1986, p.13). Pode se dizer que a história tradicional é a historia dos vencedores que apresenta o passado como verdadeiro por meio de argumentos políticos transformando até fatos míticos em fatos históricos.

Neste sentido, as fontes em educação podem contribuir significativamente para a reconstrução da história da educação por meio dos documentos oficiais das escolas, dos livros de chamada, das fotos dos prédios e da comunidade escolar como um todo. A análise destas fontes, dependendo do posicionamento do historiados, trará a tona as contradições existentes em cada contexto histórico dando voz aos silenciados pela história produzida pela classe dominante. 


\section{Conclusão}

A partir do exposto, conclui-se que na realização da análise de um determinado fato histórico o pesquisador deve conhecer as principais concepções da história para que desta forma possa refletir, a luz de um referencial teórico, sobre a problemática educacional da sociedade. Ressalta-se que as fontes históricas são produções humanas, produzidas intencionalmente, ou não, deste modo todo o historiador deve confrontar as fontes históricas relativas a um mesmo acontecimento ou a uma mesma época, pois, essas fontes divergem, não apenas na avaliação, mas até na descrição dos fatos. Destacando que, independente do referencial escolhido, o pesquisador em história e historia da educação deve ter o compromisso para com a história da humanidade, de maneira a contribuir para com aqueles que dela estejam excluídos.

O pesquisador deve ter também o entendimento de que o conhecimento é infinito e que a história nunca está acabada, pois, é um processo da humanidade e todo o conhecimento produzido em um determinado período histórico pode ser reescrito posteriormente, ou seja, o historiador questiona uma tese já defendida, a partir desses questionamentos elabora uma antítese que posteriormente chegará a uma nova tese comprovando, ou não, sua antítese, no entanto, sua tese só será "verdadeira" até que um novo pesquisador a coloque em questão e a partir daí elabore uma nova tese.

Deste modo, a tarefa do historiador consiste na compreensão e na explicação dos acontecimentos históricos a luz de um referencial teórico, toda a sua produção sobre a história traz a sua individualidade, a sua percepção e a sua compreensão sobre a humanidade. Portanto, na produção da história como ciência, o recorte histórico, a escolha das fontes e, principalmente o método a ser utilizado para a análise dos fatos históricos serão determinantes no posicionamento de cada historiador perante a sociedade.

\section{Referências}

ANDERY, Maria Amália Pie Abib. Para compreender a ciência: uma perspectiva histórica/ Maria Amália Pie Abib Andery. et al. Rio de Janeiro: Garamond, 2007.

ARANA, Hermas Gonçalves. Positivismo reabrindo o debate/Hermas Gonçalves Arana. Campinas, SP: Autores Associados, 2007. (Coleção Educação Contemporânea).

ABAGNANO, Nicola, Dicionário de Filosofia. Tradução da $1^{\text {a }}$ edição brasileira; Coordenado e revisado por BOSI, Alfredo; revisão da tradução e tradução dos novos textos BEDETTI, Ivone

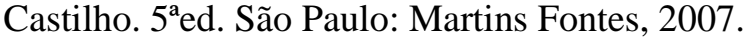

CAMBI, Franco. História da pedagogia. São Paulo: Editora UNESP, 1999.

CAVAZOTTI, Maria Auxiliadora. O projeto republicano de educação nacional na versão de José Veríssimo. São Paulo: Annablume, 2003.

CHAUI, Marilena. O que é ideologia. São Paulo: Brasiliense, 1980.

COMTE, Auguste. Curso de filosofia positiva: Discurso sobre o espírito positivo; Discurso preliminar sobre o conjunto do positivismo; catecismo positivista/ Auguste Comte; seleção de textos de José Arthur Giannotti; traduções de José Arthur Giannotti e Miguel Lemos. São Paulo: Abril Cultural, 1978. (Os pensadores)

GLÉNISSON, Jean. Iniciação aos estudos históricos. 3. ed. São Paulo; Rio de Janeiro: DIFEL, 1979. 
KOSIK, Karel. Dialética do concreto. São Paulo: Paz e Terra, 2002.

LE GOFF, Jacques (Dir) A história nova. 2a Ed. São Paulo: Martins Fontes, 1993.

LOMBARDI, José Claudinei. Fontes, história e historiografia da educação/ José Claudinei Lombardi e Maria Isabel Moura Nascimento, (orgs). Campinas, SP: Autores Associados: HISTEDBR; Curitiba, PR: Pontifícia Universidade Católica do Paraná (PUCPR); Palmas, PR: Centro Universitário Diocesano do Sudoeste do Paraná (UNICS); Ponta Grossa, PR: Universidade Estadual de Ponta Grossa (UEPG), 2004. (Coleção Memória da Educação).

LOPES, Eliane Marta Teixeira Lopes. Perspectivas Históricas da Educação. São Paulo: Ática, 1986.

LOWY, Michael. As aventuras de Karl Marx contra o Barão de Munchhausen: Marxismo e positivismo na sociologia do conhecimento. São Paulo: Busca vida 1998.

MARROU, Henri Irénée História da Educação na Antiguidade / tradução do Prof. Mário Leôndidas Casanova / São Paulo, E.P.U., Brasília, INL, 4ª Reimpressão, 1975.

MARX, Karl. Contribuição à critica da economia política. 3.ed.São Paulo: Martins Fontes, 2003.

MARX, Karl e ENGELS Friedrich. Manifesto do partido comunista. Cap. I. Burguesia e proletariado, Calvino, 1975.

A ideologia alemã. 2. ed., Livraria Editora Ciências Humanas Ltda. São Paulo - SP, 1979.

PONCE, Aníbal. Educação e Luta de Classes. / Aníbal Ponce; Traduzido do original em espanhol/ publicado por J. Hector Matera - Buenos Aires, 1957. Tradução para a língua portuguesa de José Severo de Camargo Pereira - São Paulo: Fulgor, 1963.

SAVIANI, Dermeval. Educação: do senso comum à consciência filosófica/ Dermeval Saviani. São Paulo: Cortez Editora: Autores Associados, 1986.

In. Fontes, história e historiografia da educação/ José Claudinei Lombardi e Maria Isabel Moura Nascimento, (orgs). Campinas, SP: Autores Associados: HISTEDBR; Curitiba, PR: Pontifícia Universidade Católica do Paraná (PUCPR); Palmas, PR: Centro Universitário Diocesano do Sudoeste do Paraná (UNICS); Ponta Grossa, PR: Universidade Estadual de Ponta Grossa (UEPG), 2004. (Coleção Memória da Educação).

In. NASCIMENTO, Isabel Moura. [et al.], (orgs). Instituições Escolares no Brasill: conceito e reconstrução histórica. Campinas, SP: Autores Associados: HISTEDBR; Sorocaba, SP: Uniso; Ponta Grossa, PR: UEPG, 2007. - (Coleção memória da educação).

DUARTE, Newton. Pedagogia histórico-critica e luta de classes na educação escolar. Campinas: Autores Associados, 2012.

SCHAFF, Adam. História e Verdade. São Paulo: Martins Fontes, 1995. 


\section{Notas}

1 Doutoranda em Educação pela Universidade Estadual de Ponta Grossa - UEPG. Professora do Departamento de Educação (COL) - DEED Universidade Estadual de Ponta Grossa. E-mail: lupadilha5@yahoo.com.br

${ }^{2}$ Doutora em Educação pela Universidade Estadual de Campinas. Professora da Pós Graduação em Educação - Mestrado e Doutorado e do Departamento de Educação da Universidade Estadual de Ponta Grossa. misabel@lexxa.com.br

3 O termo História não tem uma única e precisa definição, historicamente comportando sentidos diferenciados. Por História entendemos os fatos ou acontecimentos de uma sociedade ou indivíduos. O mesmo termo, história, é usado para designar o campo do conhecimento que faz a narração metódica desses mesmos fatos ocorridos na vida dos povos. O termo história também é usado para designar o conjunto de conhecimentos sobre as transformações do passado dos homens. Outra designação para história é para referir-se ao conjunto das obras referentes à história (LOMBARDI, 2004, p. 142).

${ }^{4} \mathrm{O}$ conhecimento é infinito, deste modo a verdade de um determinado objeto ou período histórico é relativa, pois, com o passar do tempo e a partir de novos processos de elaboração do conhecimento, ela tende a ser substituída por outras verdades, o que não quer dizer que a verdade era falsa, mas sim que o conhecimento evoluiu (SCHAFF, 1995).

5 As fontes históricas podem ser: Textuais - livro de atas, ofícios, cartas, memorandos, relatórios, etc; Iconográficas - fotografias, slides/diapositivos, negativos, negativos em vidro, mapas, plantas etc.; Audiovisuais - filmes de rolo, fitas, etc.; Orais - depoimentos, entrevistas, histórias de vida; museológicos - tecido, couro, metal, etc., produzidos pelos homens ou provenientes da natureza.

${ }^{6} \mathrm{O}$ positivismo surge na Europa, em fins do século XVIII princípio do século XIX, como uma utopia críticorevolucionária da burguesia absolutista, para tornar-se, no decorrer do século XIX, até os nossos dias, uma ideologia conservadora identificada como a ordem industrial/burguesa estabelecida (LOWY, 1998, p. 18). Positivismo - termo empregado pela primeira vez por Saint-Simon (discípulo de Condorcet), para designar o método exato das ciências e sua extensão para a filosofia. Foi adotado por Comte para sua filosofia - a característica do Positivismo é a romantização da ciência, sua devoção como único guia da vida individual e social do homem, único conhecimento, única moral, única religião possível. (ABBAGNANO, 2007).

${ }^{7}$ O Materialismo Histórico Dialético surgiu na Europa ocidental, a partir da publicação do Manifesto Comunista de 1848 por Karl Marx e Friedrich Engels. O materialismo designa um conjunto de doutrinas filosóficas que rejeita a existência de um princípio espiritual, e assim, liga a realidade a matéria e as modificações ocorridas na sociedade.

Recebido: junho-15 Aprovado: dezembro-15 